\title{
Desafios do planejamento urbano na expansão das cidades: entre planos e realidade
}

Urban planning challenges in the expansion of cities: between plans and reality

Silvia Maria Santana Andrade Lima[a], Wilza Gomes Reis Lopes[a] @

[a] Universidade Federal do Piauí (UFPI), Teresina, PI, Brasil

Como citar: Lima, S. M. S. A., Lopes, W. G. R., \& Façanha, A. C. (2019). Desafios do planejamento urbano na expansão das cidades: entre planos e realidade. urbe. Revista Brasileira de Gestão Urbana, 11, e20190037. https://doi.org/10.1590/2175-3369.011.e20180037

\section{Resumo}

A expansão do perímetro urbano para construção de conjuntos habitacionais ou mesmo para regularizações de ocupações espontâneas é uma realidade nas cidades brasileiras. À medida que a cidade cresce, são aterrados córregos e lagoas, cortadas encostas e ocupadas margens de rios e áreas naturais. As questões socioambientais estão cada vez mais presentes nas propostas de planejamento e ordenamento do território. Neste artigo, é analisada a relação entre os planos diretores e a expansão urbana, diante dos novos desafios ambientais apresentados ao planejamento e à gestão urbana, tendo como foco a cidade de Teresina, no Piauí. Foram realizadas revisão bibliográfica e discussão do tema. Foram executados levantamento e análise documental de instrumentos regulatórios, planos e programas municipais, observando os planos diretores e a legislação que os ampara. Os principais problemas urbanos destacados em seus planos foram: a drenagem urbana precária, a falta de aterro sanitário, o desmatamento, as queimadas e as dificuldades na mobilidade e no transporte urbano. 0 novo plano diretor Agenda Teresina 2030 e a legislação mais recente apontam para melhores cenários no futuro da cidade, mas ainda é preciso maior eficiência na construção da sustentabilidade urbana.

Palavras-chave: Expansão urbana. Gestão urbana. Plano diretor.

\section{Abstract}

The expansion of the urban perimeter for the construction of housing estates or even regularization of spontaneous occupations are realities in Brazilian cities. As the city grows, streams and ponds are landed, cut off slopes and occupied banks of rivers and natural areas.-Socio-environmental questions are increasingly present in the planning and organization proposals of the territory. In this article, the relationship between the master plans and urban expansion is analyzed, considering the new environmental challenges presented to urban planning and management, focusing on the city of Teresina, Piauí. A bibliographic review and discussion of the theme were carried out. A survey and documentary analysis of regulatory instruments, plans, and municipal programs was also carried out, observing the

SMSAL é arquiteta, professora, doutora em Desenvolvimento e Meio Ambiente, e-mail: slima@ufpi.edu.br 
Executive Plans and the legislation that protects them. The main urban problems highlighted in their plans were the precarious urban drainage; lack of landfill; the deforestation; the burnings; difficulties in mobility and urban transportation. The new Teresina Master Plan Agenda 2030 and more recent legislation point to better scenarios in the future of Teresina. However, there is still a need for greater efficiency in the construction of urban sustainability.

Keywords: Urban expansion. Urban management. Master plan.

\section{Introdução}

A crise ambiental atual é apontada, por muitos estudiosos, como reflexo da busca desenfreada do homem pelo crescimento econômico e da ocupação ampla e intensa dos espaços naturais (Leff, 2001; Sachs-Jeantet, 2007; Acselrad, 2009). Essa busca pelo crescimento tem exaurido os recursos e reduzido o poder da natureza de se recompor. Tal situação fica mais evidente nas cidades, onde o meio físico, como suporte das atividades humanas, é mais requisitado, refletindo-se na ocupação e na organização do território (Rodriguez \& Silva, 2013).

Os crescimentos urbano e populacional trazem problemas ambientais e de gestão. Há demanda crescente por habitação, infraestrutura, saneamento, serviços de saúde e educação, entre outros equipamentos. À medida que a cidade cresce, são aterrados córregos e lagoas, cortadas encostas e ocupadas margens de rios e áreas naturais. A expansão do perímetro urbano para construção de conjuntos habitacionais ou mesmo para regularizações de ocupações espontâneas é uma realidade nas cidades brasileiras. Tudo isso, segundo Braga (2001, p. 95), "[...] tem causado a degradação progressiva de áreas de mananciais, com a implantação de loteamentos irregulares e a instalação de usos e índices de ocupação incompatíveis com a capacidade de suporte do meio".

Novas propostas para o planejamento e o ordenamento do território avançam na perspectiva de um olhar sistêmico, envolvendo vontade política, participação da sociedade, qualidade no projeto urbano, forma de distribuição e consumo do espaço, acesso equânime aos serviços públicos e aos assentamentos humanos, respeitando as especificidades locais (econômicas, sociais e ambientais), chamada por Rolnik (2008) de "pacto socioterritorial".

Como observa Souza (2016), enquanto planejamento remete ao futuro, a gestão está relacionada ao presente. Para Rodriguez \& Silva (2013, p. 337), gestão ambiental é “[...] um processo de aplicação, gestão e exploração de recursos e serviços dos espaços e áreas do território a partir de uma perspectiva ambientalmente racional e equilibrada".

A investigação sobre a expansão urbana com o aumento do perímetro urbano, por meio da incorporação de novas áreas ao espaço da cidade, é muito importante para se conhecer o principal mecanismo de produção de novas áreas urbanas e saber como população, incorporadores imobiliários e Estado atuam, além de observar como a legislação pode ser mais eficiente na gestão do espaço urbano, socialmente mais justo e sustentável. Segundo Nascimento \& Matias (2011, p. 66), "[...] tal investigação fornece elementos que permitem caracterizar, entre outros aspectos, a estruturação interna e a distribuição das classes sociais na cidade, bem como o principal mecanismo de produção de novas áreas urbanas, que é a valorização fundiária".

A legislação urbana é o principal instrumento de controle no processo de uso e ocupação do solo. No entanto, esse instrumento, de competência do governo municipal, nem sempre se mostra eficiente, provocando, muitas vezes, efeitos perversos, como áreas mais valorizadas que outras e terras estocadas para especulação imobiliária, empurrando a população mais carente para a periferia com infraestrutura e serviços precários ou para áreas ambientalmente inadequadas (Braga, 2001).

Weise et al. (2013, p. 138), ao investigarem medidas para combater a especulação imobiliária, reafirmaram que "[...] o Plano Diretor é o instrumento de planejamento urbano de longo prazo, que consegue regular a oferta de terrenos e imóveis bem como os preços oferecidos". Ou seja, o plano diretor, 
instrumento regulador municipal, de forma geral, tanto pode ter efeitos positivos como negativos na construção da sustentabilidade urbana.

Santos \& Montandon (2011, p. 42) alertam que poucos planos diretores no Brasil "[...] incorporam mecanismos e instrumentos capazes de dar efetividade à política ambiental [...]", sendo observada também essa falta de instrumentos e de efetividade em outras áreas, como saneamento ambiental, mobilidade, acesso à terra e à moradia.

A cidade de Teresina, criada, em 1852, para ser a capital do Estado do Piauí, apresenta problemas semelhantes a outras cidades brasileiras, marcados por uma expansão urbana crescente e desigual. Apesar de ser considerada uma cidade planejada na sua origem, efetivamente seu primeiro plano urbano foi em 1969, o Plano Diretor Local Integrado (PDLI). Em 1977, foi elaborado o I Plano Estrutural de Teresina (I PET). Depois, houve o II Plano Estrutural de Teresina (II PET), de 1988, com legislação em vigor até 2002. Nesse ano, foi desenvolvido o Plano de Desenvolvimento Sustentável - Teresina Agenda 2015 (Teresina, 2002), que, acrescido de legislações complementares, a partir de 2006, corresponde oficialmente ao plano diretor de Teresina. Em 2015, foi elaborada a Agenda Teresina 2030: A Cidade Desejada, com propostas de implementação até o ano de 2030 (Teresina, 2015b).

No entanto, o que se constata, inicialmente, é que esses planos não incorporam mecanismos, como legislação, recursos e ações efetivas, para vencer os problemas socioambientais presentes na cidade. Diante do exposto, é importante estudar a expansão urbana de Teresina, conhecer essa realidade e sua relação com os instrumentos legais existentes.

Neste artigo, serão analisados aspectos relacionados à expansão urbana e à incorporação de novas áreas na cidade, abordando o papel dos planos diretores na contenção da expansão e os novos desafios apresentados à gestão urbana, tendo como foco a cidade de Teresina, no Piauí.

Como metodologia, foi realizada a análise dos planos diretores de Teresina (PDLI, I PET, II PET, Teresina Agenda 2015 e Agenda Teresina 2030), enfocando as diretrizes constantes nesses planos e as ações implementadas, voltadas para o controle da expansão urbana, como mudanças no perímetro e relação crescimento populacional e territorial urbano, além das ações direcionadas à implantação de áreas verdes e de áreas de proteção ambiental. Na pesquisa, foram considerados dados populacionais e de renda do IBGE, legislação municipal, projetos de estruturação urbana realizados e mapas da Prefeitura Municipal de Teresina, bem como imagens do Google Maps (2013). Para elaboração da parte gráfica, os mapas e os dados do IBGE foram trabalhados no ArcGIS (10.3).

\section{Expansão e planos urbanos em Teresina}

A cidade de Teresina teve como modelo de ocupação uma malha reticular ortogonal, com quadras de 100 metros, separadas por ruas de 11 metros aproximadamente, tendo como marco zero a Igreja de Nossa Senhora do Amparo e sua praça frontal. Conhecido como Plano Saraiva (1852), foi seu primeiro plano urbano, definido pelo sistema viário, pela distribuição e pela localização das instituições públicas, com malha urbana abrangendo $3 \mathrm{~km}$ de quarteirões desenhados no sentido norte-sul e tendo como limites, a oeste, o rio Parnaíba e, a leste, o rio Poti (Bastos, 1994; Façanha, 1998; Lima, 2002).

Nunes \& Abreu (1995, p. 96) destacam essa proposta urbana como novidade, para a época, no planejamento de cidades, afirmando que:

Ao contrário de outras aglomerações urbanas que surgiam espontaneamente, o plano de construção de Teresina previa sua extensão, seu ponto central - a igreja do Amparo - a partir do qual deveriam se orientar todas as outras medidas de demarcação da cidade de Teresina e o traçado das ruas em linha reta, cruzando-se umas com as outras, dando-lhe a forma de tabuleiro de jogo de damas.

A criação da cidade de Teresina foi idealizada pelo então presidente da província do Piauí, Conselheiro José Antônio Saraiva, tendo como plano urbano um traçado regular inicial, com medidas de ruas e quadras, para a implantação da cidade. No entanto, não apresentava, como ocorre na atualidade, previsões de expansão, sugestões de densidades ou gabaritos, por exemplo. Com o crescimento 
populacional e a necessidade de mais espaço, extrapolou-se a ocupação urbana do traçado proposto por Saraiva, que chegou a ser reproduzido no início, mas tendo sido depois abandonado, quando se passou a ter um crescimento mais "espontâneo" de ruas e quadras.

De acordo com Bastos (1994), na segunda década após a transferência da capital, o número de habitantes era superior a 20 mil pessoas (Tabela 1). Em 1900, a malha geométrica proposta no Plano de Saraiva já abrigava população de 45.316 habitantes, compreendendo $13,55 \%$ da população total piauiense, equiparando-se a outras capitais, como Fortaleza (CE), que, na mesma época, apresentava 48.368 habitantes (IBGE, 2010b; Bastos, 1994).

Tabela 1 - População dos municípios de Teresina e Fortaleza (1854 a 1900)

\begin{tabular}{cccccc}
\hline Municípios & $\mathbf{1 8 5 4}$ & $\mathbf{1 8 5 5}$ & $\mathbf{1 8 7 2}$ & $\mathbf{1 8 9 0}$ & $\mathbf{1 9 0 0}$ \\
\hline Teresina & $11.820^{*}$ & $13.122^{*}$ & 21.692 & 31.523 & 45.316 \\
Fortaleza & -- & -- & 42.458 & 40.902 & 48.368 \\
\hline
\end{tabular}

Fonte: IBGE (2010b), Bastos (1994)*.

A partir da década de 1950, houve o aumento populacional em Teresina. Entre 1940 e 1950, a taxa de crescimento da população urbana foi de 48,19\%, enquanto na década seguinte (1950/1960) foi de 91,24\%. Esse crescimento populacional ocorreu, entre outros fatores, por causa da melhoria nas ligações urbanas, no transporte e nas comunicações, da implantação de equipamentos urbanos e institucionais e também do aumento no fluxo migratório (Lima, 1995).

A cidade de Teresina passou a concentrar, após a década de 1950, percentuais acima de $30 \%$ do contingente total urbano do Piauí, chegando, em 1991, a taxas de 40,76\%, confirmando a tendência de polarização urbana e a prevalência da capital em relação aos demais municípios do Estado. Esse fato é chamado por Mendes (1996) de "macrocefalia" e por Lima (1995) de "megalópole estadual". Tal crescimento se deu não somente em função do incremento natural da população residente, mas, sobretudo, em decorrência do fluxo migratório, vindo de cidades de pequeno porte e de áreas rurais em direção ao município.

Os fluxos migratórios cresceram na década de 1970, época de maior expansão do espaço urbano teresinense. Foi consolidado o sistema viário de penetração da cidade, com aberturas de grandes avenidas, e se iniciou a ocupação da região leste, além do rio Poti. Lima (2002) destaca a importância da criação da ponte sobre o rio Poti, ligando a BR-343 ao centro da cidade, e da posição estratégica de Teresina, no entroncamento com os Estados do Maranhão, do Ceará, de Pernambuco e da Bahia, para o crescimento da cidade.

Nesse período, foram construídas não só estradas e pontes, mas também habitação popular, instalação de empresas de economia mista nas áreas de água e esgoto, como a companhia de Águas e Esgotos do Piauí S.A. (AGESPISA), de 1964, e na área de energia, como a companhia Centrais Elétricas do Piauí S.A. (CEPISA), de 1962, além da implantação da Universidade Federal do Piauí (UFPI), em 1970 (Façanha, 1998; Lima, 2002; Nascimento, 2007)

Percebe-se a participação do poder público no crescimento da cidade, pois, como observa Nascimento (2007, p. 205), há forte presença do Estado "[...] como indutor da dinâmica urbana, nas esferas federal, estadual e municipal".

Nas décadas de 1970 e 1980, surgiram novos bairros, a partir da implantação de conjuntos habitacionais populares, como Conjunto Primavera (1966) e Mocambinho (1979), na região norte; Conjunto Monte Castelo (1966), Parque Piauí (1968), Bela Vista (1976), Saci (1979) e o Promorar (1982), na região sul; Itararé (1977), Tancredo Neves (1985) e Renascença (1986), na região sudeste. Até a extinção do Banco Nacional de Habitação (BNH) em 1986, foram construídas em Teresina mais de 38 mil unidades habitacionais, abrigando mais de 150 mil pessoas (Teresina, 2012). Dessa forma, a implantação desses conjuntos impulsionou o crescimento e a expansão da cidade, pois muitos deles estavam situados fora da malha urbana.

Como apontam Rodrigues \& Veloso (2015), elementos, por exemplo, a instalação de empreendimentos importantes, a abertura de eixos viários e, principalmente, a implantação de conjuntos 
habitacionais, destacam-se como os principais vetores da expansão de Teresina. Ressalta-se que, ao promover a construção de grandes conjuntos habitacionais na periferia da cidade, em decorrência dos altos custos de uma implantação mais próxima, em razão do valor da terra e dos fatores ligados à disponibilidade de grandes lotes, além de incentivar o crescimento horizontal, os vazios urbanos, os desmatamentos, os contrastes espaciais e sociais, o poder público terminou por ampliar a dicotomia centro-periferia.

Diante da expansão urbana verificada e do agravamento dos problemas socioambientais, os investimentos em infraestrutura e a provisão de moradias foram insuficientes para resolver o déficit habitacional. Entre os anos de 1970/1980, foi registrado um grande número de invasões/ocupações, tanto em terrenos públicos como privados, como descrevem Lima \& Rodrigues (2006, p. 122):

[...] marcada por fortes tensões sociais nas práticas de uso e ocupação do solo, fruto do acirramento dos conflitos entre os distintos agentes que atuam no espaço urbano - os imobiliários, o movimento de luta pela moradia e o próprio Estado -, para o que concorreram, de forma decisiva, alguns fatores, como a inadequação dos instrumentos urbanísticos então vigentes a uma complexa realidade urbana, a ausência de políticas públicas de enfrentamento da questão e a extinção do SFH e do BNH.

A expansão urbana da cidade fez nascer a necessidade da elaboração de estudos e planos de ordenação, que, desde a fundação de Teresina, só ressurgiram no final da década de 1960, com seu primeiro plano de desenvolvimento urbano, o Plano Diretor Local Integrado (PDLI), de 1969 (Nunes \& Abreu, 1995). Foi elaborado por uma empresa baiana de consultoria - a Construções e Planejamento (COPLAN S.A.) - com financiamento do Ministério do Interior, por meio do Serviço Federal de Habitação e Urbanismo (SERFHAU), do Programa de Financiamento para o Planejamento Urbano (FIPLAN) e do Banco Nacional de Habitação (BNH) (Teresina, 1969).

O PDLI deixou um diagnóstico sobre Teresina, mas, por falta de uma legislação que o amparasse e também de recursos financeiros, não obteve muitos resultados na prática. Foram implantados o sistema viário radioconcêntrico e o anel viário - hoje, Avenida Miguel Rosa. Segundo Nascimento (2007), esse plano apresentou o primeiro zoneamento da cidade, e, para Lima (2012, p. 367), “[...] a não materialização da maior parte desse plano trouxe consequências drásticas para a cidade, que crescera sem instrumentos de regulação de seu espaço".

Em 1977, foi elaborado, então, o I Plano Estrutural de Teresina (I PET) pelo Instituto de Planejamento e Administração Municipal (IPAM), em convênio com a Superintendência do Desenvolvimento do Nordeste (SUDENE), a Comissão Nacional de Política Urbana (CNPU), a Prefeitura Municipal de Teresina (PMT) e a Universidade de Brasília (UnB). Esse plano foi instrumentalizado pela Lei no 1.591, de 31 de agosto de 1978 (Teresina, 1977).

Nas recomendações do I PET, estava a implantação do zoneamento da cidade de acordo com funções, com base em eixos de polarização, e o reforço da estrutura radioconcêntrica, proposta para a cidade no plano anterior, de 1969, além de legislação que, segundo Lima (2012, p. 367), instituiu "[...] figuras jurídicas, como o aforamento de terrenos do patrimônio municipal, o parcelamento, uso e ocupação do solo urbano e o Código de Edificações". Foram observadas também a preocupação com o adensamento urbano e a subutilização de infraestruturas e equipamentos urbanos existentes, propondo padrões de densidade por zona e perímetro urbano compatível de 100 hab/ha, até 1985 (Teresina, 1977).

Em 1983, foram iniciados estudos para a elaboração de um novo plano, o Plano Diretor de Desenvolvimento Urbano (PDDU), que não se concretizou, mas gerou informações sobre a condição da cidade de Teresina na época (Lima, 2012).

Em abril de 1987, foi realizado o seminário Planejando Teresina, com o propósito de obter sugestões e soluções para o agravamento dos problemas urbanos e a formulação do II Plano Estrutural de Teresina (II PET). Esse plano foi oficializado pela Lei no 1.932, de 16 de agosto de 1988, tendo como diretrizes, no setor político-administrativo, a descentralização pública municipal, por meio da implantação de administrações regionais e maior participação da comunidade.

Nas diretrizes de uso e ocupação do II PET, foram incentivadas a descentralização do espaço de urbanização inicial entre rios (bairro Centro) e a ocupação da região leste (Socopo/Pedra Mole e Todos 
os Santos/São Sebastião). Foi proposta ainda a restrição de crescimento da região sul, por ser área de topografia acidentada e de proteção do manancial de abastecimento d'água, e também da região norte, por causa da concentração de lagoas e áreas alagadiças. Estabeleceu-se como metas: novo perímetro urbano, com projeções de área para ocupação até o ano de 2000; densidade urbana de 70 hab/ha; indicação de zonas residenciais de interesse social, em áreas próximas ao local de emprego e à rede de infraestrutura; implantação de conjuntos habitacionais, com aproveitamento dos vazios urbanos, mecanismos tributários e incentivos fiscais para estimular o uso de terrenos desocupados e regularização de ocupações em área de conflito; criação do Fundo Municipal de Terras; determinação de não ocupação de áreas de mananciais e ao longo dos rios, entre outras. 0 II PET estava acompanhado de leis no sentido de viabilizar a sua implantação (Teresina, 1988).

Em 1992, ocorreu a primeira revisão do II PET, e, em 1993, foram sancionadas novas leis, procurando atualizar a ocupação do solo urbano e os códigos de obras e edificações, em decorrência do processo de verticalização e crescimento populacional para os territórios mais ao norte da cidade, além do rio Poti, inclusive com a delimitação do perímetro urbano e dos bairros naquela área (Lima, 2002, 2012).

Em linhas gerais, as diretrizes do II PET comungavam com a Constituição de 1988, em que se tinha a participação da população, embora não de maneira efetiva, e preocupações sociais estavam presentes. No entanto, a legislação, para garantir a aplicação do plano e melhor se adequar à Constituição, só ocorreu em 1993. Na prática, o que se observou foi um crescimento urbano disperso, em que as regiões norte e sul se tornaram áreas de conjuntos habitacionais e população de baixa renda, enquanto a região leste, com crescimento de população de médio e alto padrão, converteu-se na área mais valorizada da cidade (Rodrigues \& Veloso, 2015; Castelo Branco, 2012)

Para Lima \& Rodrigues (2006, p. 129),

[...] os esforços da prefeitura foram insuficientes para resolver a crise urbana, pois, em 1998, Teresina assistiu à maior ocupação de toda a sua história com a Vila Irmã Dulce, com 5.000 mil famílias, demonstrando a fraqueza do governo local para atender a grande demanda por habitação.

Também, a ocupação de margens de rios e lagoas na zona norte tornou-se um problema socioambiental. Até 2000, ainda vigoravam a legislação de 1988 e as leis que a alteraram. Essa legislação ficou ultrapassada diante das mudanças ocorridas na cidade, perceptível no aumento da expansão urbana, crescimento das ocupações espontâneas e na verticalização. Esse processo, segundo Lima (2011, p. 8), deixa "[...] antever a insuficiência dos instrumentos urbanísticos para responder às exigências da dinâmica espacial e social".

Em 2001, após a aprovação do Estatuto da Cidade, Lei no 10.257, de 10 de julho de 2001 (Brasil, 2001), o poder público municipal viu-se obrigado a elaborar novo plano diretor para se adequar à lei federal, bem como definir um novo instrumento que pudesse reorientar seu desenvolvimento urbano, já que as leis vigentes estavam defasadas. Para isso, instalou, em agosto de 2001, o Congresso da Cidade para discussão e elaboração do plano diretor de Teresina, que foi aprovado em dezembro de 2002, sob a Lei no 3.151 (Lima, 2012). Em 2006, a Lei no 3.151/2002 foi alterada pela Lei no 3.558/2006, aprovando o plano diretor e o nomeando o Plano de Desenvolvimento Sustentável - Teresina Agenda 2015 (Teresina, 2017).

O plano Teresina Agenda 2015, de 2002, dividia-se em 14 grandes áreas: Requalificação Urbana, Meio Ambiente e Paisagem, Regeneração Cultural, Operações Urbanas Consorciadas, Integração Regional, Integração Municipal, Sistema de Mobilidade, Acessibilidade e Transportes, Habitação Social, Dotação de Equipamentos Sociais, Saneamento Ambiental, Desenvolvimento Econômico, Desenvolvimento do Turismo e Atração de Investimentos. 0 plano diretor, denominado Teresina Agenda 2015, estava dividido em três cenários: Teresina que Temos, em que se identificavam os problemas da cidade; Teresina que Queremos, em que era apontado o potencial esperado; e Teresina que Faremos, em que se descreviam as ações previstas para sua implementação (Teresina, 2002).

O documento Teresina Agenda 2015, de 2002, não veio acompanhado de legislação, sendo regulamentado e atualizado, em 2006, pela Lei no 3.558 (Teresina, 2006). A partir de 2006, havia a legislação para implantação de polos geradores de tráfego, estudo prévio do impacto de vizinhança, direito de preempção, leis para organização do espaço urbano, parcelamento do solo urbano, criação das 
zonas de preservação ambiental, ocupação do solo urbano e perímetro urbano, promulgadas em 2006; Código de Obras e Edificações e Código Sanitário, de 2007; e leis sobre as Zonas Especiais de Interesse Social (ZEIS), de 2008 (Teresina, 2017), voltadas para a gestão urbana.

A administração municipal centrou-se em projetos setoriais e na captação de recursos, estando alguns desses projetos em execução, enquanto outros ainda não saíram do papel (Quadro 1).

Quadro 1 - Alguns projetos do Plano de Requalificação Urbana (PRU), Teresina 2010/2020

\begin{tabular}{|c|c|c|}
\hline Projeto & Descrição & Situação \\
\hline $\begin{array}{l}\text { Lagoas do } \\
\text { Norte }\end{array}$ & $\begin{array}{c}\text { Concentrado na região centro-norte. Objetivo de melhorar as condições } \\
\text { ambientais das regiões de lagoas próximas ao encontro dos rios Poti e } \\
\text { Parnaíba, promovendo a urbanização adequada, com a preservação } \\
\text { ambiental, além da dotação de infraestrutura urbana e serviços } \\
\text { institucionais, com divisão em quatro áreas. }\end{array}$ & $\begin{array}{l}\text { Primeira etapa } \\
\text { concluída }\end{array}$ \\
\hline $\begin{array}{l}\text { Urbanização da } \\
\text { Vila da Paz }\end{array}$ & $\begin{array}{l}\text { Envolve a requalificação de assentamentos em área de risco na Vila da } \\
\text { Paz, localizada próximo ao Estádio Albertão, na região centro-sul, } \\
\text { incluindo moradias, dotação de equipamentos sociais, como teatro, } \\
\text { centro esportivo e outros, além de intervenção urbanística. }\end{array}$ & Projeto \\
\hline $\begin{array}{l}\text { Mercado São } \\
\text { José }\end{array}$ & $\begin{array}{c}\text { Projeto de restauração e reabilitação do Mercado Central, ou Mercado } \\
\text { Velho de Teresina, é parte integrante do processo de regeneração } \\
\text { cultural do centro histórico da cidade. }\end{array}$ & Em construção \\
\hline $\begin{array}{l}\text { Terminais de } \\
\text { Integração }\end{array}$ & $\begin{array}{c}\text { Faz parte do plano diretor de transportes e mobilidade urbana de } \\
\text { Teresina, com implementação de oito terminais nas áreas periféricas e } \\
\text { três terminais na zona central. }\end{array}$ & Em construção \\
\hline $\begin{array}{l}\text { Centro } \\
\text { Empresariais Sul } \\
\text { e Norte }\end{array}$ & $\begin{array}{l}\text { Propostas que unem expansão urbana, ordenamento e estruturação do } \\
\text { território, atração de investimentos e investidores e aprimoramento da } \\
\text { logística regional, considerando o futuro anel rodoferroviário de Teresina. }\end{array}$ & Em andamento \\
\hline $\begin{array}{l}\text { Corredores } \\
\text { Ambientais Poti } \\
\text {-Parnaíba }\end{array}$ & $\begin{array}{l}\text { Pretende aliar planejamento urbano, proteção ambiental e } \\
\text { desenvolvimento econômico com intervenções compartilhadas, } \\
\text { revitalização e renaturalização dos rios para agregar valor ao espaço } \\
\text { urbano, pela criação de espaços de fruição, denominados polos de } \\
\text { lazer e natureza norte (Encontro dos Rios), nordeste (Embrapa, Ciências } \\
\text { Agrárias e Zoobotânico) e sul (Curva São Paulo). }\end{array}$ & Em andamento \\
\hline $\begin{array}{l}\text { Aeroporto de } \\
\text { Teresina }\end{array}$ & $\begin{array}{l}\text { Projeto de reforma do aeroporto Senador Petrônio Portella com } \\
\text { intervenções tanto no aeroporto em si quanto em seu entorno. }\end{array}$ & Projeto paralisado \\
\hline $\begin{array}{l}\text { Sistema } \\
\text { Conexões- } \\
\text { Pontes }\end{array}$ & $\begin{array}{c}\text { Duplicação de vias (acesso à região norte, duplicação da avenida Poti } \\
\text { Velho e duplicação da avenida Josue de Moura Santos), construção de } \\
\text { pontes sobre o rio Poti (ponte Leonel Brizola e ponte Anselmo Dias) e } \\
\text { acessos. }\end{array}$ & $\begin{array}{l}\text { Concluídas as } \\
\text { pontes Leonel } \\
\text { Brizola e Anselmo } \\
\text { Dias }\end{array}$ \\
\hline $\begin{array}{l}\text { Parque Estação } \\
\text { Cidadania }\end{array}$ & $\begin{array}{c}\text { Faz parte do processo de regeneração cultural do centro histórico, } \\
\text { parque de esporte, cultura e lazer no entorno da antiga estação } \\
\text { ferroviária de Teresina. }\end{array}$ & Concluído \\
\hline
\end{tabular}

Fonte: Teresina $(2014,2017)$.

Como previsto, o plano Teresina Agenda 2015, que foi recentemente revisado, resultou no plano Agenda Teresina 2030: A Cidade Desejada, publicado em 4 de agosto de 2015 (Teresina, 2015b).

Nesse plano, foram apresentadas propostas para os próximos 15 anos, tendo no eixo Cidade Sustentável temas, como Saneamento Básico, Habitação e Situação Fundiária, Infraestrutura Urbana, Mobilidade Urbana e Transporte Público. Já no eixo Governança Eficiente, está proposta a "eficácia e eficiência na aplicação dos recursos públicos", além de recomendações para aumentar a participação da população e buscar ações integradas e sistêmicas entre os órgãos da estrutura organizacional. Quando se faz referência à eficiência e às ações integradas entre os órgãos municipais, o documento esclarece a dificuldade em "[...] evitar o paralelismo das ações, causa de desperdício de recursos humanos, técnicos, financeiros e operacionais" (Teresina, 2015b, p. 91-92).

No entanto, apesar das propostas de participação popular nas decisões administrativas, por meio do Orçamento Popular e dos Conselhos Municipais, ainda são processos que precisam ser aprimorados, pois são fortemente criticados. Como afirma Lima (2012, p. 373), o processo participativo do plano diretor, "a despeito do discurso que evocava a participação da sociedade, teve um caráter mais consultivo, pois, de 
fato, não houve uma intervenção direta dos distintos segmentos sociais, nem sequer de todas as representações dos movimentos sociais". No entanto, a questão da participação "ampla" é discutível, já que, na realidade, o observado em Teresina é a baixa frequência nas convocações e assembleias propostas pela Prefeitura Municipal de Teresina para discutir os problemas da cidade. A participação envolve "mentalidade cidadã", questões políticas e engajamento, e, como afirma Antonello (2013, p. 252), “[...] está pontuado de obstáculos que poderão ser removidos pela conscientização da sociedade sobre o valor da participação popular".

A instrumentalização do plano proposto (2002) e de sua revisão (2015) aconteceu lentamente e com alterações constantes. As leis de delimitação do perímetro urbano, parcelamento do solo e ocupação do solo do Teresina Agenda 2015, de 2002, só foram publicadas em outubro de 2006, sofrendo alterações nos anos subsequentes, sendo as últimas já consequência das atualizações do plano Agenda Teresina 2030, em 2015 e 2016, demonstrando maior agilidade desse último. Foram criadas, em 2015, as leis do Imposto Predial e Territorial Urbano (IPTU) progressivo, que garante a função social da propriedade (Lei no 4.781), de drenagem (Lei no 4.724) e de zonas de expansão (Lei no 4.851), enquanto o Código Sanitário (Lei no 4.975) é de 2016 (Teresina, 2017).

\section{Relação entre os planos diretores e a expansão urbana em Teresina}

A falta de efetividade das propostas contidas nos planos diretores, apontada por Santos \& Montandon (2011), em estudos sobre planos diretores em cidades brasileiras, deve-se, em muitos casos, à falta de implementação da legislação. Faz-se necessário rapidez na promulgação de leis que ampare e respalde esses planos, para que não fiquem apenas no discurso e em propostas.

A existência de baixa densidade e espraiamento, com forte presença de vazios urbanos, foi apontada como realidade a ser modificada em todos os planos estudados, desde o PDLI de 1969. Dessa forma, demonstra-se a necessidade de aprimoramento, seja nos planos, seja na legislação que os ampara, ao se observar a realidade da elasticidade dos perímetros no decorrer do tempo em Teresina (Figura 1).

O perímetro urbano de Teresina sofreu várias alterações nas últimas décadas, no sentido de acrescentar áreas, ou em consequência de ocupações urbanas ou por causa da construção de conjuntos habitacionais, a despeito da permanência de vazios urbanos dentro do tecido urbano consolidado e das baixas densidades. Na legislação de 2006, observou-se uma tendência no sentido de reduzir ou mesmo congelar esse perímetro, sendo as alterações resultado do surgimento de novos bairros a partir de desmembramento de antigos, ou ainda a criação de núcleos urbanos isolados, como é o caso do Núcleo Urbano Santana, aglomerado urbano fora do perímetro urbano (Lei no 3.647/2007), e do condomínio fechado Fazenda Real Residence (Lei no 4.281/2012).

Observa-se que não são apenas os conjuntos populares que proporcionam o espraiamento horizontal da cidade. Os condomínios horizontais e os loteamentos fechados, característicos das cidades contemporâneas, têm se tornado indutores do crescimento horizontal das cidades, na medida em que precisam ocupar grandes áreas para sua implantação. Segundo Silva et al. (2015, p. 177), em Teresina, até 2014, foram identificados 68 condomínios horizontais fechados ou loteamentos fechados, "[...] que estão distribuídos em várias partes da cidade, destinados a atender diversos grupos socioeconômicos". Alguns deles estão localizados em áreas periféricas da cidade, como o Aldebaran Ville, com 500 lotes, Terras Alphaville Teresina, com 1.075 lotes, e Fazenda Real Residence, com 800 lotes, todos na região leste, o Alphaville Teresina, com 757 lotes, na região sudeste, e o Condomínio Bella Codipi, com 176 lotes, na região norte, que podem impulsionar o crescimento da mancha urbana.

Na Figura 1, em que se apresenta a distribuição de renda média salarial em Teresina, é possível visualizar conjuntos habitacionais populares, como o Jacinta Andrade, na região norte, com 4.500 unidades, e também condomínios fechados de alto padrão, como o Alphaville na região leste, que tem induzido o crescimento da cidade. Observa-se ainda grandes áreas sem urbanização, como a Fazenda Santa Rosa, inserida no perímetro urbano, localizada ao norte, depois do encontro dos rios Parnaíba e Poti, e antes do Conjunto Habitacional Jacinta Andrade. 


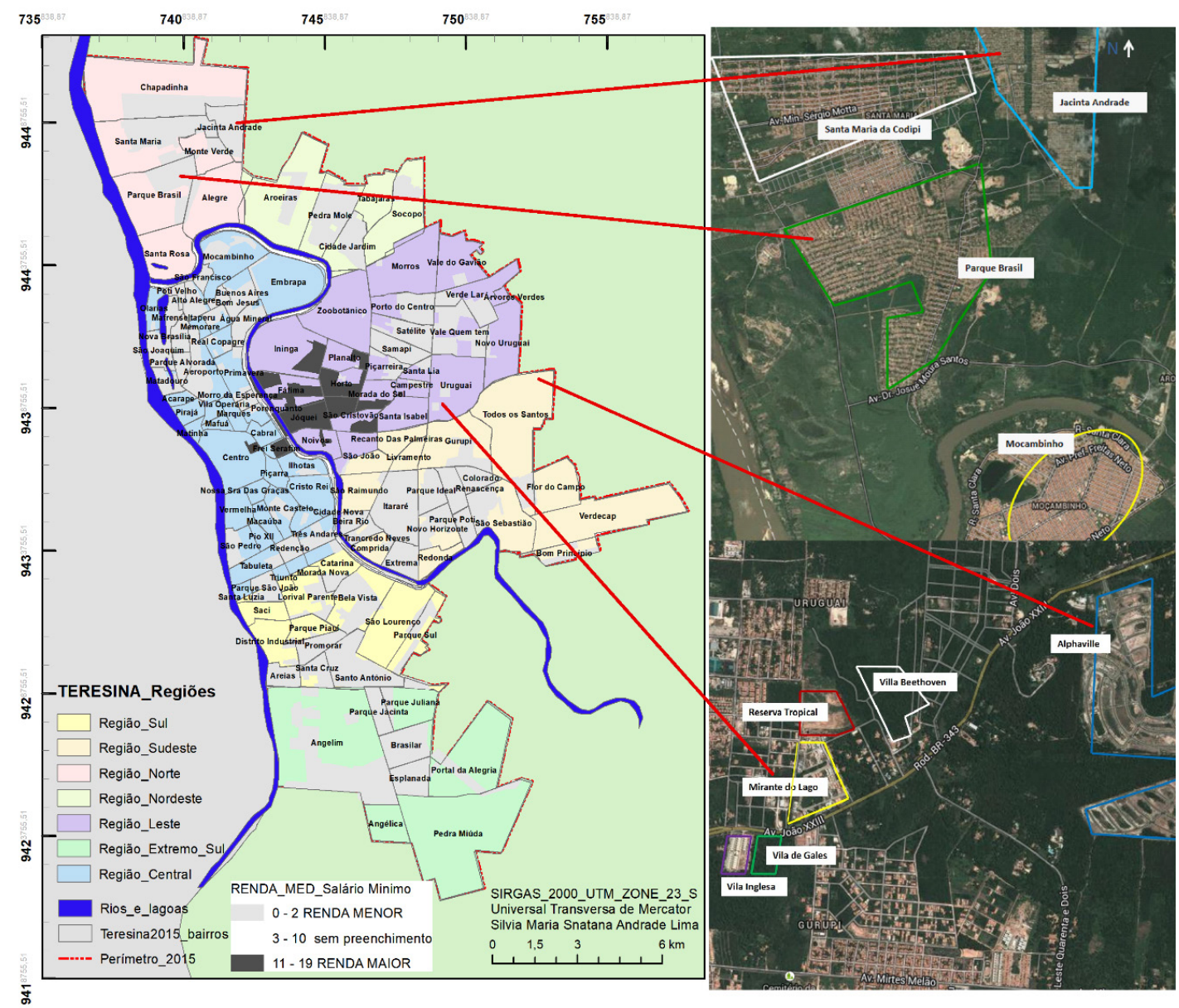

Figura 1 - Regiões urbanas de Teresina, com distribuição das maiores e menores rendas em média salarial (em salário mínimo - SM) e imagens parciais das regiões norte e leste. Fonte: IBGE (2010b, c), Teresina (2015a), Google Maps (2013) trabalhados no ArcGIS (10.3).

Com a aprovação da Lei no 4.423, de 16 de julho de 2013, o governo municipal criou mais nove bairros em Teresina, que passou de 112 para 123, em função de novas delimitações e nomeações em seu território. Dessa forma, na região norte, surgiram os bairros Chapadinha, Santa Maria, Jacinta Andrade, Monte Verde, Parque Brasil e Alegre; na região leste, foram criados os bairros Cidade Jardim e Árvores Verdes; na região sudeste, foi criado o bairro Flor do Campo; e na região sul, foram criados os bairros Portal da Alegria, Pedra Miúda e Angélica (Teresina, 2017).

A última modificação que ocorreu no perímetro urbano de Teresina foi em 26 de outubro de 2015, com a Lei no 4.831, que incorporou novas áreas, em razão de novos loteamentos e ocupações, e as previsões de expansão estão contidas na Lei no 4.851, de zonas de urbanização específica, de 21 de dezembro de 2015 (Quadro 2).

Quadro 2 - Leis que alteraram o perímetro urbano e os limites dos bairros em Teresina (2006-2015)

\begin{tabular}{|c|c|c|}
\hline N lei & Data & Alteração \\
\hline$n^{\circ} 3.559$ & 2006 & Altera perímetro urbano de Teresina \\
\hline$n^{\circ} 3.647$ & 2007 & Cria Núcleo Urbano Santana \\
\hline$n^{\circ} 3.789$ & 2008 & Altera o perímetro da Zona Urbana de Teresina na região de Árvores Verdes. \\
\hline$n^{\circ} 3.906$ & 2009 & Altera o perímetro da Zona Urbana de Teresina na região de Todos os Santos \\
\hline$n^{\circ} 4.281$ & 2012 & Cria Núcleo Urbano Fazenda Real \\
\hline$n^{\circ} 4.423$ & 2013 & Altera perímetro de bairros e cria outros \\
\hline$n^{\circ} 4.831$ & 2015 & Altera perímetro urbano de Teresina \\
\hline$N^{\circ} 4.851$ & 2015 & Cria zonas de urbanização específica (zonas de expansão) \\
\hline
\end{tabular}

Fonte: Teresina (2017). 
Em 2000, o perímetro urbano de Teresina englobava 27.502,68 hectares, sendo o de maior área territorial das últimas décadas (1993-2015). Apontado como um dos pontos negativos no Congresso da Cidade, de 2001, assim como os grandes vazios urbanos, em 2006 esse perímetro foi reduzido para $25.084,40$ hectares, mas, em 2015, foi ampliado para 26.411,95 hectares. Entre os argumentos para a nova ampliação da área do perímetro, em 2015, foi a incorporação de espaços já urbanizados, seja com loteamentos de alto padrão, seja com ocupações espontâneas. A ampliação não garantiu a inclusão de todas as áreas urbanizadas, restando ainda duas áreas na legislação de Teresina fora desse perímetro e tratadas como urbanas: o Núcleo Urbano Santana (Lei no 3.647/2007), que fica a sudeste, e o Núcleo Urbano Fazenda Real Residence (Lei no 4.281/2012), na região mais a leste.

Na Figura 2, apresenta-se o mapa de Teresina com os perímetros urbanos de 2000, 2010 e 2015, visualizando-se as áreas urbanizadas, rurais e urbanas, segundo IBGE (2005). Ou seja, diante dos vastos territórios da capital piauiense e da baixa produtividade apresentada por sua zona rural, em que o setor primário representa $0,6 \%$ do total do PIB do município (IBGE, 2010a; Teresina, 2013), a expansão urbana parece não ter limites. E, apesar de o poder público concordar que está cada vez mais difícil garantir serviços de qualidade para todo o território, não se observam ações efetivas para conter esse crescimento horizontal.

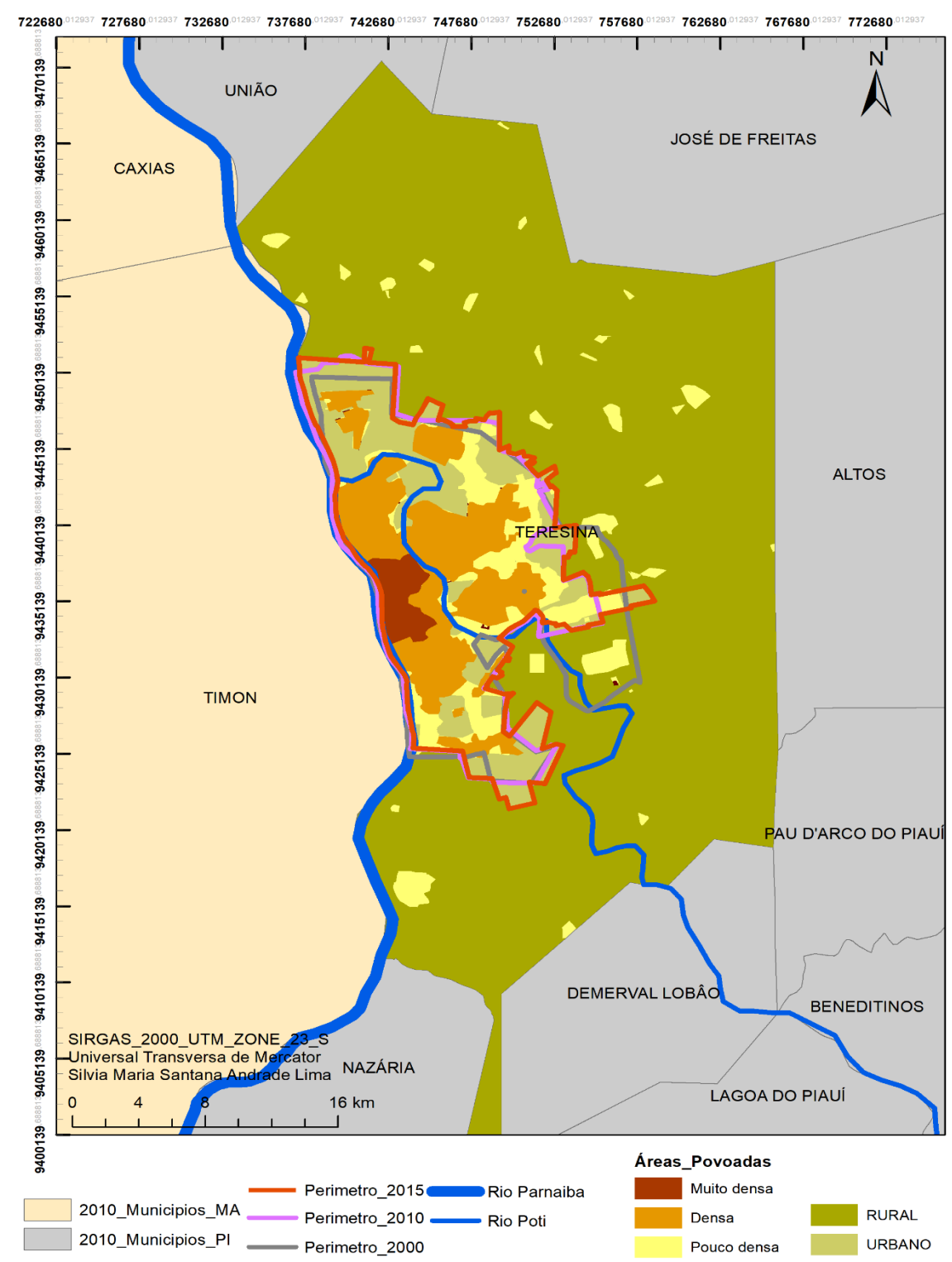

Figura 2 - Mapa de espaços povoados, rurais e urbanos, para Teresina (IBGE, 2005), e os perímetros urbanos de 2000-2010-2015. Fonte: IBGE (2005, 2010c), Teresina (2015b), desenvolvido no ArcGIS (10.3). 
Os principais problemas enfrentados pelo município de Teresina, destacados nos planos Teresina Agenda 2015 e Agenda Teresina 2030, foram a drenagem urbana precária, a falta de um aterro sanitário, o desmatamento, as queimadas, a mobilidade e o transporte urbano. A administração municipal tem consciência desses problemas, mas há entraves na implantação, captação de recursos, licitação e ação.

Teresina, banhada pelos rios Poti e Parnaíba, já com estimativa de população de 861.442 habitantes para 2018 (IBGE, 2018), tem sua cobertura de esgoto atingindo apenas 19,12\% de sua população, sendo que, desse percentual, apenas $15,54 \%$ são tratados (ITB, 2016). Constata-se também que, no plano diretor, a questão ambiental ainda está muito restrita à reserva de áreas para preservação.

Pela Lei no 3.563 de 2006 (Teresina, 2017), foram criadas as zonas de preservação ambiental, delimitando áreas apenas na zona urbana, esquecendo-se da zona rural. As áreas de preservação concentram-se às margens dos rios Poti e Parnaíba, desconsiderando-se outros espaços dentro do tecido urbano, inclusive as áreas em que se registra a presença de baixões (grotões e riachos).

Na legislação de parcelamento do solo (Lei no 4.780/2015), tem-se a previsão de $10 \%$ do total do empreendimento para a preservação de áreas com vegetação, no caso dos terrenos inseridos do perímetro urbano, e de $12 \%$ nas zonas de urbanização específica, equivalente às zonas de expansão (Lei no 4.851/2015). Existe a obrigatoriedade do plantio de árvores em empreendimentos horizontais (Lei no 4.555/2014) e a campanha de incentivo à arborização de ruas e praças (Lei no 3.903/2009) (Teresina, 2017). No entanto, não se observa a previsão de preservar as matas nativas nem de proibir sua total remoção, no momento de implantar o loteamento, ocorrendo, assim, o desmatamento total de terrenos durante a implantação de empreendimentos imobiliários, como pode ser observado na execução do Condomínio Alphaville, em Teresina, em 2013 (Figura 3).

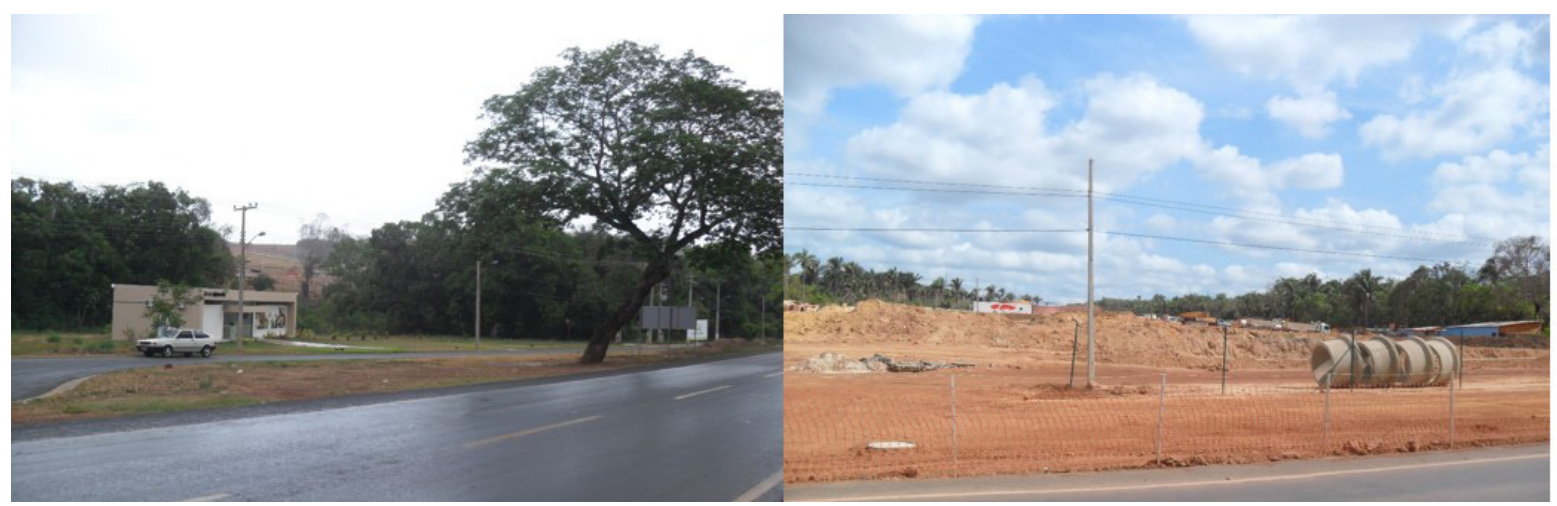

Figura 3 - Implantação do condomínio Alphaville em Teresina, em 2013. Fonte: autores (2013).

A manutenção da cobertura vegetal é considerada um indicador de equilíbrio e qualidade ambiental, sendo, na visão de Silva \& Romero (2008), indispensável para a redução da poluição, a proteção de nascentes e mananciais, o melhoramento do microclima urbano e a manutenção da biodiversidade.

Zhao et al. (2013), em pesquisa que envolveu 286 cidades, entre 1989 e 2009, abrangendo as províncias da China Continental, constataram que, nessas cidades, diferentemente do que se observou em Teresina, a urbanização caminhou de maneira linear, com o aumento da cobertura do espaço verde, em decorrência, principalmente, das políticas governamentais de apoio ao verde urbano. Zhou \& Wang (2011), em estudo na área metropolitana de Kunming, na China, de 1992 a 2009, sobre as mudanças nos padrões de espaços verdes, também constataram esse aumento do solo vegetado internos às zonas urbanas; no entanto, nas áreas periféricas, apontaram perdas de terras agrícolas e, em menor intensidade, de cobertura florestal, alertando para a necessidade de proteção desses espaços suburbanos.

Já Streglio et al. (2013), que estudaram a relação entre o processo de urbanização e a redução da cobertura vegetal no município de Goiânia (GO), constataram que, apesar do acompanhamento de planos diretores em toda sua história de urbanização, o município apresentou grandes perdas de cobertura vegetal entre 1986 e 2010, mesmo diante dos esforços de preservação dos recursos naturais e criação de 
parques urbanos. Esse processo se assemelha à cidade de Teresina, que tem como agravante as elevadas temperaturas e a baixa umidade do ar no período seco, de agosto a novembro.

No entanto, a retirada total da vegetação na implantação de assentamentos é uma prática recorrente, como observa Foresti (1990), podendo refletir, posteriormente, na demora de recuperação de cobertura vegetal, quando da implantação de condomínios de alto padrão, ou o que é pior, em se tratando de assentamentos de baixa renda, implicar redução definitiva dessa cobertura vegetal.

Segundo a Lei Complementar no 3.561, de 20 de outubro de 2006, do município de Teresina, sobre parcelamento de solo, no capítulo IX, que trata dos critérios para parcelamento do solo, artigo 55 (Teresina, 2017), não podem ser incluídas como áreas verdes:

$\S 1^{\circ}$ As nesgas de terra não aceitas como área verde ou de uso institucional não podem ser consideradas no cálculo dos percentuais indicados.

$\S 2^{\circ} 0$ espaço livre decorrente da confluência de vias de circulação só pode ser computado como área verde ou área institucional quando puder conter um círculo com raio de $15 \mathrm{~m}$ (quinze metros).

$\S 3^{\circ}$ Não se enquadram como áreas verdes ou áreas de uso institucional os cantos e fundos de quadras, bem como qualquer outra nesga de terra com largura inferior a $20 \mathrm{~m}$ (vinte metros).

Apesar de considerar alguns critérios para não permitir a inclusão de sobras ou pequenos terrenos como áreas verdes, ou mesmo rotatórias de vias de circulação, a destinação, tanto das áreas de preservação como das áreas verdes na legislação de Teresina, não prevê a garantia da qualidade desses espaços nem de quem seria a responsabilidade de implantação de equipamentos para usufruto de toda a comunidade.

Além desses aspectos, destaca-se o agravamento dessa questão, quando se trata da destinação de áreas vegetadas, como nos casos de condomínios fechados (Lei no 4.780, de 19 de agosto de 2015) (Teresina, 2017), cujas áreas verdes podem ficar internas ao empreendimento, não sendo acessível ao restante da comunidade.

A Lei no 4.851, de 21 de dezembro de 2015 (Teresina, 2017), que define parâmetros para urbanização nos espaços de expansão fora do perímetro urbano (zonas de urbanização específica), amplia a porcentagem para áreas verdes de $10 \%$ para $12 \%$, no entanto continua sem tratar de conservação de matas nativas. Apresenta avanço também na proposta que destina metade desse percentual de $12 \%$ para escolha da implantação pela Prefeitura e fora do parcelamento, possibilitando ser mais bem aproveitada e em benefício de toda a cidade. Contudo, a mesma lei de parcelamento, no capítulo V, artigo 35, coloca a possibilidade de aterrar lagoas e modificar cursos d'água, assim propondo: “[...] as lagoas e cursos d'água só podem ser modificados, aterrados ou desviados após a autorização da Prefeitura Municipal, após apresentação de projeto que especifique e justifique os serviços".

Outro aspecto incorporado nos últimos planos foi a implantação das Zonas Especiais de Interesse Social (ZEIS), como nos casos das vilas Nova Brasília (2007), Parque Brasil (2008), Árvores Verdes (2008), Embrapa (2012), Real Copagre (2012) e Jerusalém (2012). No entanto, para cada nova ocupação ou assentamento de interesse social, há uma nova lei de criação de ZEIS. Ou seja, não há previsão ou reserva de áreas futuras para esse tipo de assentamento, sendo, apenas, reguladas aquelas já existentes no contexto urbano de Teresina (Teresina, 2017).

Um dado positivo, que poderia auxiliar na contenção dos vazios urbanos, na reserva de áreas para interesse social e na qualidade urbana, seria a Lei no 4.781 de 2015, que implantou o Imposto Predial e Territorial Urbano (IPTU) progressivo e a função social da propriedade, assim como a Lei no 4.975 de 2016, que instituiu o Código Sanitário de Teresina, já que cria mecanismos legais para que o órgão público possa cumprir a função social da propriedade, coibindo, entre outros aspectos, vazios urbanos especuláveis, definindo infrações e penalidades no trato da saúde pública, dos solos, das águas e dos resíduos (Teresina, 2017).

O plano Agenda Teresina 2030 (Teresina, 2015b) e a legislação mais recente apontam para melhores cenários no futuro de Teresina, porém com correções, como: propor zonas de preservação ambiental para as áreas urbana e rural; prever reserva natural e verde em novos empreendimentos imobiliários, 
deixando claro que o empreendedor é também responsável por sua estrutura; prever banco de terras para a implantação de ZEIS; respeitar lagoas e cursos d'água; coibir mais fortemente, por meio do IPTU progressivo, os vazios urbanos especuláveis; relacionar alteração do perímetro urbano com densidade populacional e distribuição da rede de serviços públicos etc.

Os planos diretores são conquistas da redemocratização do país, que criaram condições para tornar as cidades lugares melhores de se viver, mas devem ser aperfeiçoados na busca de equilíbrio, justiça e ambientes urbanos mais saudáveis (Santos \& Montandon, 2011).

A aplicabilidade das propostas dos planos diretores, segundo Antonello (2013, p. 252), passa pela participação popular, dando as "[...] condições necessárias para ampliar a atuação social na produção do espaço". Já Santos \& Montandon (2011) colocam que, muitas vezes, faltam os instrumentos legais para efetivá-los. Na realidade, é um processo que precisa ser aperfeiçoado, pois envolve vontade política, recursos financeiros e questões culturais.

\section{Considerações finais}

O planejamento e a gestão ambiental devem considerar o equilíbrio entre o homem e seu ambiente como sistemas que interagem de forma complexa, em uma teia de interligação que afeta todo o conjunto. Em um primeiro momento, os planos buscavam atender às necessidades imediatas da oferta urbana (solo, infraestrutura e equipamentos), dando ênfase à infraestrutura e ao uso do solo, sem considerar os aspectos socioambientais. Atualmente, busca-se atender à demanda urbana, principalmente visando ao bem-estar dos cidadãos e aos critérios de desenvolvimento sustentável, levando em consideração as inter-relações entre a sociedade e a natureza. Não basta apenas atender à demanda por infraestrutura nem somente delimitar as áreas de preservação; a gestão urbana deve promover a combinação de ações que promovam a distribuição equânime dos benefícios urbanos com qualidade.

Foi observado que, em Teresina, a delimitação do perímetro urbano está mais relacionada às ocupações espontâneas e à implantação de conjuntos habitacionais e condomínios fechados, ou seja, à necessidade de terras e moradias, pressionada por questões sociais ou incorporações imobiliárias, do que por critérios técnicos de densidade, condições de suporte do meio ou presença de infraestrutura.

Percebe-se também que a preservação ambiental leva em consideração, principalmente, as margens dos principais rios de Teresina (Parnaíba e Poti), enquanto negligencia córregos e riachos que alimentam esses corpos d'água, que são tratados como galerias, de águas pluviais ou de esgoto, ou ainda esquece a contaminação da água e do solo pela falta de tratamento satisfatório do esgoto e do lixo em Teresina.

Falta também integração entre os órgãos municipais e menos burocracia para maior agilidade entre planos, projetos, recursos e implementação de obras. Os recursos reduzidos e a burocracia nos serviços públicos são grandes entraves nas administrações públicas, contudo a administração municipal de Teresina já tem consciência desse problema de gestão, ao apontar a existência do paralelismo das ações entre alguns setores. A velocidade com que os espaços são ocupados pela população que precisa de abrigo, nem sempre ambientalmente adequados, e a pressão por aprovação de implantação de grandes conjuntos habitacionais periféricos, por causa do relevante interesse social, são o oposto da lentidão na aprovação de leis que regulam a ocupação e a expansão do solo urbano, ou ainda na captação de recursos; enfim, legislação, recursos e ações não são, efetivamente, tão céleres para vencer os problemas socioambientais presentes na cidade, ocorrendo, dessa forma, grande distanciamento entre planos e ação.

Ressalta-se ainda a ampliação da participação popular, principalmente por causa das novas mídias, mas ainda se enfrenta resistência por questões culturais de não participação, por achar que a população jamais será ouvida, ou por questões políticas, em que o antagonismo de ideias predomina sobre a cidadania.

0 acelerado processo de transformação pelo qual passam as cidades hoje exige um planejamento também mais dinâmico, em que todos os dados e os planos setoriais se integrem em uma visão global e o monitoramento e o acompanhamento de ações sejam contínuos. 


\section{Agradecimentos}

Os autores agradecem ao Conselho Nacional de Desenvolvimento Científico e Tecnológico - CNPq (Processo 449752/2014-3), pelo apoio financeiro.

\section{Referências}

Acselrad, H. (Org.). (2009). A duração das cidades: sustentabilidade e risco nas políticas urbanas (2. ed.). Rio de Janeiro: Lamparina.

Antonello, I. T. (2013). Potencialidade do planejamento participativo no Brasil. Sociedade \& Natureza, 25(2), 239254. http://dx.doi.org/10.1590/S1982-45132013000200003.

Bastos, C. A. (1994). Dicionário Histórico e Geográfico do Estado do Piauí. Teresina: Fundação Cultural Monsenhor Chaves.

Braga, R. (2001). Política urbana e gestão ambiental: considerações sobre plano diretor e o zoneamento urbano. In P. F. Carvalho \& R. Braga (Org.). Perspectivas de gestão ambiental em cidades médias (pp. 95-109). Rio Claro: LPMUNESP.

Brasil. (2001). Lei no 10.257, de 10 de julho de 2001. Regulamenta os arts. 182 e 183 da Constituição Federal, estabelece diretrizes gerais da política urbana e dá outras providências. Brasília: Diário Oficial da União.

Castelo Branco, A. F. V. (2012). A ação do Estado e do mercado imobiliário no processo de segregação sócioespacial em bairros da Zona Leste de Teresina (Tese de doutorado). Instituto de Geociências e Ciências Exatas, Universidade Estadual Paulista Júlio de Mesquita Filho, Rio Claro.

Façanha, A. C. (1998). A evolução Urbana de Teresina: agentes, processos e formas espaciais (Dissertação de mestrado). Universidade Federal de Pernambuco, Recife.

Foresti, C. (1990). Proposta Metodológica para o estudo ambiental e da estruturação do espaço urbano em áreas metropolitanas. In Anais do VI Simpósio Brasileiro de Sensoriamento Remoto. Manaus: INPE. Recuperado em18 de agosto de 2016, de http://marte.sid.inpe.br/col/dpi.inpe.br/marte@80/2008/08.15.19.31/doc/336-340.pdf

Google Maps. (2013). Imagem de Teresina. Recuperado em 10 de dezembro de 2016, de https://www.google.com.br/maps/@-5.0502418,-42.7955089,48408m/data=!3m1!1e3

Instituto Brasileiro de Geografia e Estatística - IBGE. (2005). Áreas urbanizadas. Recuperado em 28 de janeiro de 2017, de

http://www.ibge.gov.br/home/geociencias/geografia/geografia_urbana/areas_urbanizadas/default.shtm

Instituto Brasileiro de Geografia e Estatística - IBGE. (2010a). Cidades: Teresina. Recuperado em 25 de janeiro de 2015, de http://cidades.ibge.gov.br/xtras/perfil.php?lang=\&codmun=221100\&search=piaui|teresina

Instituto Brasileiro de Geografia e Estatística - IBGE. (2010b). Censo 2010: Estatisticas. Recuperado em 28 de janeiro de 2017, de

http://www.ibge.gov.br/home/estatistica/populacao/censo2010/sinopse/sinopse_tab_brasil_zip.shtm

Instituto Brasileiro de Geografia e Estatística - IBGE. (2010c). Malha Digital de Setores Censitários. Recuperado em 28 de janeiro de 2017, de http://downloads.ibge.gov.br/downloads_geociencias.htm

Instituto Brasileiro de Geografia e Estatística - IBGE. (2018). Cidades: panorama (população). Recuperado em 13 de dezembro de 2018, de https://cidades.ibge.gov.br/brasil/pi/teresina/panorama

Instituto Trata Brasil - ITB. (2016). Ranking do saneamento: as 100 maiores cidades do Brasil. Recuperado em 2 de janeiro de 2017, de http://www.tratabrasil.org.br/datafiles/estudos/ranking/2016/tabela-das-100-cidades.pdf

Leff, E. (2001). Saber ambiental. sustentabilidade, racionalidade, complexidade, poder. Petrópolis: Vozes. 
Lima, A. J. \& Rodrigues, E. X., No. (2006). Governo local e iniciativas de políticas urbanas em Teresina. Cadernos Metrópole, 15, 113-144.

Lima, A. J. (2011). Gestão urbana e os planos diretores participativos: o que apontam os dados. In Anais do XI Congresso Luso Afro Brasileiro de Ciências Sociais (CONLAB). Salvador: UFBA. Recuperado em 20 de janeiro de 2017, de http://docplayer.com.br/3267288-Gestao-urbana-e-os-planos-diretores-participativos-o-que-apontamos-dados.html

Lima, A. J. (2012). Planos diretores e os dilemas da governança urbana no Brasil. Textos e Contextos, 2(11), 362375.

Lima, I. M. M. F. (1995). A realidade sócio-ambiental do Piauí. In R. N. M. Santana (Org.), Piauí: formação, desenvolvimento, perspectivas (pp. 429-461). Teresina: Halley.

Lima, I. M. M. F. (2002). Teresina: urbanização e meio ambiente. Scientia et Spes, 1(2), 181-206.

Mendes, G. (1996). Balaio de ideias. Teresina: Editora George Mendes.

Nascimento, E., \& Matias, L. F. (2011). Expansão urbana e desigualdade socioespacial: uma análise da cidade de Ponta Grossa (PR). RA'EGA, 23, 65-97. http://dx.doi.org/10.5380/raega.v23i0.24833.

Nascimento, F. A. (2007). Cajuína e cristalina: as transformações espaciais vistas pelos cronistas que atuaram nos jornais de Teresina entre 1950 e 1970. Revista Brasileira de História, 27(53), 195-214. http://dx.doi.org/10.1590/S0102-01882007000100009.

Nunes, M. C. P., \& Abreu, I. G. (1995). Vilas e cidades do Piauí. In R. N. M. Santana (Org.), Piauí: formação, desenvolvimento, perspectivas (pp. 83-111). Teresina: Halley.

Rodrigues, R. S., \& Veloso, F. A., Fo. (2015). O planejamento urbano enquanto fonte de pesquisa na geografia urbana histórica: análise dos planos diretores urbanos de Teresina-PI. In Anais do XIV Simpósio Nacional de Geografia Urbana. Fortaleza: SIMPURB.

Rodriguez, J. M. M., \& Silva, E. V. (2013). Planejamento e gestão ambiental: subsídios da geoecologia das paisagens e da teoria geosistêmica. Fortaleza: Edições UFC.

Rolnik, R. (2008). Pactuar o território: desafio para a gestão de nossas cidades. Revista Princípios, 97, 22-27.

Sachs-Jeantet, C. (2007). Ciudad y gestión de las transformaciones sociales. Revista URBANO, 10(16), 86-97. Recuperado em 17 de agosto de 2016, de http://revistas.ubiobio.cl/index.php/RU/article/view/380/343

Santos, O. A., Jr., \& Montandon, D. T. (2011). Síntese, desafios e recomendações. In O. A. Santos Junior \& D. T. Montandon (Org.), Os planos diretores municipais pós-estatuto da cidade: balanço crítico e perspectivas (pp. 27-56). Rio de Janeiro: IPPUR/UFRJ.

Silva, G. C., Lopes, W. G. R., \& Monteiro, M. S. L. (2015). Presença de condomínios horizontais e loteamentos fechados nas cidades contemporâneas: expansão e transformações do espaço urbano de Teresina, Piauí. Geosul, 30(59), 167-187. http://dx.doi.org/10.5007/2177-5230.2015v30n59p145.

Silva, G. J. A., \& Romero, M. A. B. (2008). Cadernos de Arquitetura e Urbanismo, 15(17), 110-135.

Souza, M. L. (2016). Mudar a cidade: uma introdução crítica ao planejamento e à gestão urbanos (11th ed ed.). Rio de Janeiro: Bertrand Brasil.

Streglio, C. F. C., Ferreira, D. T., \& Oliveira, I. J. (2013). O processo de expansão urbana e seus reflexos na redução da cobertura vegetal no município de Goiânia-Go. $R A^{\prime} E G A, 28,181-197$.

http://dx.doi.org/10.5380/raega.v28i0.32306.

Teresina. (1969). Plano Diretor Local Integrado. Teresina: Prefeitura Municipal de Teresina.

Teresina. (1977). I Plano Estrutural de Teresina. Teresina: Prefeitura Municipal de Teresina.

Teresina. (1988). Legislação Urbana de Teresina. Teresina: Prefeitura Municipal de Teresina. 
Teresina. (2002). Teresina Agenda 2015: Plano de Desenvolvimento Sustentável. Teresina: Prefeitura Municipal de Teresina.

Teresina. (2006). Plano de Desenvolvimento Sustentável - Teresina Agenda 2015. Lei no 3.558, de 20 de outubro de 2006. Recuperado em 16 de agosto de 2018, de http://semplan.35.193.186.134.xip.io/wpcontent/uploads/sites/39/2017/03/Lei- no-3.558-de-20.10.2006-PLANO-DIRETOR.pdf

Teresina. Prefeitura Municipal. (2012). Plano Local de Habitação de Interesse Social - PLHIS de Teresina - PI. Produto 3: Estratégias de ação. Recuperado em 17 janeiro de 2017, de http://semplan.teresina.pi.gov.br/wpcontent/upload/2014/09/PRODUTO-3_ESTRATEGIAS_DE_AÇÃO.pdf

Teresina. Secretaria Municipal de Planejamento e Coordenação - SEMPLAN. (2013). Diagnóstico, Avanços, Desafios: Teresina 2000-2010. Teresina: Prefeitura Municipal de Teresina. Recuperado em 25 de janeiro de 2017, de http://semplan.teresina.pi.gov.br/wp-content/uploads/2014/09/Teresina-Diagnóstico-Set-2013.pdf

Teresina. Prefeitura Municipal. (2014). Plano de Requalificação Urbana.

Teresina: SEMPLAN. Recuperado em 24 de janeiro 2017, de http://semplan.teresina.pi.gov.br/wpcontent/uploads/2014/10/APRESENTAÇÃO_PRU_TERESINA.pdf

Teresina. Secretaria Municipal de Planejamento e Coordenação - SEMPLAN. (2015a). Mapas de Teresina. Teresina: Prefeitura Municipal de Teresina. Recuperado em 28 de janeiro de 2017, de http://semplan.teresina.pi.gov.br/mapas-interativos/

Teresina. Secretaria Municipal de Planejamento e Coordenação - SEMPLAN. (2015b). Teresina Agenda 2030. Teresina: Prefeitura Municipal de Teresina. Recuperado em 1 de outubro de 2016, de http://semplan.teresina.pi.gov.br/wp-content/uploads/2015/10/Teresina-Agenda-2030.pdf

Teresina. Secretaria Municipal de Planejamento e Coordenação - SEMPLAN. (2017). Legislação Urbana. Teresina: Prefeitura Municipal de Teresina. Recuperado em 19 de janeiro de 2017, de http://semplan.teresina.pi.gov.br/wpcontent/uploads/2017/01/TERESINA-LEGISLAÇÃO-URBANA-20171.pdf

Weise, A. W., Philips, J. W., Hochheim, N., Trierweiller, A. C., \& Bornia, A. C. (2013). Contramedidas da especulação imobiliária no mercado residencial. Cadernos de Arquitetura e Urbanismo, 20(27), 124-141.

Zhao, J., Chen, S., Jiang, B., Ren, Y., Wang, H., Vause, J., \& Yu, H. (2013). Temporal trend of green space coverage in China and its relationship with urbanization over the last two decades. The Science of the Total Environment, 442, 455-465. http://dx.doi.org/10.1016/j.scitotenv.2012.10.014. PMid:23186616.

Zhou, X., \& Wang, Y. (2011). Spatial-temporal dynamics of urban green space in response to rapid urbanization and greening policies. Landscape and Urban Planning, 100(3), 268-277.

http://dx.doi.org/10.1016/j.landurbplan.2010.12.013.

\section{Editor: Rodrigo Firmino.}

Recebido: Dez. 18, 2018

Aprovado: Fev. 18, 2019 